\title{
FLASHING SPEEDS OF INCANDESCENT SIGNAL LAMPS.*
}

BY

\author{
A. G. WORTHING. \\ Nela Research Laboratories.
}

SYNOPSIS.

This paper represents a portion of a study of the theory of signalling units involving incandescent lamps, which was undertaken in response to a request from the National Research Council and the U. S. Signal Corps for the development of a unit for use in daylight signalling.

Filament Characteristics Involved.-Various factors involving signalling speed, where the telegraphic dot-and-dash signals are produced by the flashing of an incandescent lamp, are discussed broadly in a contrast of tungsten with carbon for filament material. The most important factors are: (I) the change in resistance with change in temperature; $(2)$ the quantity of energy required to heat the filament through a given temperature range; (3) the total emissive power of the filament material; (4) the maximum temperature of a flash, and (5) the efficiency of the radiation in producing vision. For lamps of equal voltage, life and luminous flux, a tungsten filament responds more rapidly than carbon during the heating portion of a flash by a factor of six or seven; during the cooling portion of a flash by a factor of 2.5 .

Observed Specds and Their Comparison with Computed Values.-A photometric method of studying the performance of lamps on flashing is described and results obtained with various lamps are presented. These are compared with computed values based on steady current measurements and the supposition that a lamp filament on heating or cooling passes through a succession of steady states. The agreement is quite satisfactory, excepting the case of a filament immersed in hydrogen, where the discrepancy may be ascribed to ionization effects.

Speed Function.-A simple function $Q$ (equation I2), involving only steady current measurements of wattage, resistance

* Communicated by the Author. 
and temperature in the neighborhood of the maximum temperature of a flash, together with a knowledge of the thermal capacity of the filament, will serve quite accurately in rating lamps as to their flashing speeds.

Some Fundamental Generalizations.-(I) The time required for a filament to heat to approximately its maximum brightness exceeds greatly the time required in cooling to effectively zero brightness.

(2) The higher the maximum temperature of a flash, the greater is the speed of the flash.

(3) The smaller the filament, the greater is the speed of the flash.

(4) The less the resistance in a circuit external to a flashing tungsten lamp, the greater is the speed of the flash.

(5) The speed of flashing for a given filament at a given temperature in various atmospheres-including in vacuo-is greater, the greater the gas loss.

(6) For lamps of the same open filament construction, the same luminous flux, and the same average life at a fixed voltage, the speed of flashing is greater, the greater the gas loss.

Ribbon Filaments Versus Wire Filaments. - The quantity of material in a ribbon filament is less than that in an equivalent wire filament. Therefore, in gas-filled lamps, by going from a wire filament to a ribbon filament we may obtain either a considerable increase in signalling speed, or, often without a reduction in speed, a higher efficiency by choosing an atmosphere involving a decreased gas loss. For example, a lamp containing a ribbon filament in argon, proposed in response to the above request, when compared with a lamp containing a wire filament in nitrogen which was its nearest competitor, indicated speeds and efficiencies in favor of the ribbon filament lamp of about 1.6 and I.25.

\section{IMPORTANCE OF VARIOUS FACTORS AS INDICATED IN A CONTRAST OF TUNGSTEN AND CARBON FILAMENT LAMPS.}

It is a matter of common observation that an ordinary tungsten lamp lights up more quickly than does an equivalent carbonfilament lamp. The contrast, most evident when the older types of carbon lamps are considered, is still quite appreciable for the 
later Gem lamps containing the metallized graphite filament. This difference in response between tungsten and carbon filaments may be readily analyzed to show the various factors which determine the flashing speeds of signal lamps.

The fundamental law descriptive of the behavior of all incandescent lamps which is applicable here, states that the rate of supply of energy as heat to a filament is equal to the rate of dissipation of energy by the filament plus the rate of storage of energy in the filament. The dissipation of energy may take place through radiation, through ordinary heat conduction to filament supports or through gaseous conduction and convection. In vacuum lamps, of course, no gas losses are present. This law is expressed in equation form as

$$
V I=f(T)+c m \frac{d T}{d t}
$$

where $V$ represents potential drop, $I$ current, $f(T)$ rate of dissipation of energy at a temperature $T, c$ specific heat, $m$ filament mass, and $\frac{d T}{d t}$ rate of increase or decrease of temperature. The three terms of the equation correspond respectively to the three rates enumerated in the underlying fundamental law. For brevity of reference these will often be referred to as supply rate, dissipation rate and storage rate. During the first part of a flash the storing up of energy in the filament is by far the predominating method by which the supply is disposed of. With increasing temperature the dissipation method becomes more and more effective until, at the maximum temperature, the dissipation rate equals the supply rate and the storage process ceases.

Evidently those factors which affect the flashing speeds of signal lamps do so through affecting the supply rate, the dissipation rate, the amount of energy to be stored up, and, since flashes are measured from a brightness instead of a temperature standpoint, the percentage change in brightness accompanying a given percentage change in temperature.

In contrasting the flashing properties of different filaments, there appear certain factors more or less independent: (I) the change in filament resistance with change in temperature; (2) the quantity of energy required to heat the filament through a given temperature range; (3) the total emissive power of the filament material; (4) the maximum temperature of the flash, and (5) the

Vor. I9I, No, 1I42-I7 
efficiency of the radiation from the filament in producing vision. It is interesting and worth while to consider how and to what extent these factors are of importance individually. With this in mind, let us contrast the heating up portions of the flashes (omitting for the present that portion of the flash during which cooling. occurs) of equivalent vacuum tungsten and Gem lamps in circuits, encountered in signalling practice, containing constant voltage sources with no appreciable resistance external to the lamp.

Factor (I) relating to changes in filament resistance with changes in temperature concerns the supply rate. In tungsten an exceptionally large increase in resistance-of the order of thirteenfold-occurs in heating from room temperatures to ordinary incandescent temperatures; in the Gem lamp the resistance change is practically nil. In the constant voltage circuit met with in signalling practice, a tungsten filament, in consequence of its low initial resistance, experiences a proportionally large initial current, and a correspondingly large initial supply rate. The initial storage rate is equally great. With the gradual increase in temperature and resistance, a gradual diminution occurs in the supply rate until the maximum temperature is reached. The supply rate for the Gem filament in a like circuit is practically constant. Comparing now tungsten and Gem lamps of the same voltage and the same wattage, in which therefore the final supply rates are equal, cause is seen for a great advantage in flashing speed through the use of tungsten. Computations according to a method cletailed later, indicate that a tungsten filament operated in a circuit with a constant supply rate reaches 90 per cent. of its maximum brightness in an interval about 1.6 times that required when operated in the constant voltage circuit of normal signalling. Most of the actual difference in time is represented by a delay in heating through the lower range of temperature. The advantage of a tungsten filament over a Gem filament in the heating portion of a flash resulting from changes in resistance may thus be set down as about I.6.

Factor (2), relating to the thermal capacity of the lamp filament, concerns the storage of heat in the filament. Various measurements on Gem and tungsten lamp show, for the samevoltage, wattage and operating temperature, that the heat stored up in the Gem filament is about 1.3 times that stored up in the tungsten filament. The advantage of a tungsten filament over a 
(iem filament resulting from differences in the thermal capacity wi the filaments is thus of the order of I.3.

Factor (3) relating to total emissive powers concerns the dissipation rate. The total emissive power of tungsten - the measure of its rate of radiating energy compared with a black body at the same temperature-is generally low, though increasing rather rapidly with increasing temperatures. The total emissive power of a Ciem filament is comparatively high and does not change rapidly with changing temperatures. The radiation rates for the lamps being compared represent practically the dissipation rates as defined, and, at their maximum temperatures, are therefore approximately equal to their supply rates. But, on the passage of the flaments through the lower temperature ranges, due to the relatively smaller emissive power (expressed in terms of the value at the maximum temperature) of tungsten, there is relatively a reduced rate of radiation of energy by that metal and thereby a comparatively increased storage rate. Though the advantage is definitely in favor of tungsten, the effectiveness of this factor is small, and for our comparison, may be considered negligible.

Factor (4), relating to the maximum temperature of operation. concerns the supply rate, the dissipation rate and the quantity of heat stored up. Comparing two tungsten lamps of the same voltage and wattage, but with operating temperatures of $2200^{\circ} \mathrm{K}$, ${ }^{1}$ approximately that of the Gem lamp, and $2400^{\circ} \mathrm{K}$ approximately that of the low wattage vacuum tungsten lamp, we find that the change in the dimension of the filament in going from the lamp with the lower operating temperature to that with the higher operating temperature is considerable, and that the increase in the quantity of heat stored up resulting from the increased temperature range is much more than offset by the less amount of material heated. The net advantage resulting from the higher temperature is about I.6. The effect on the supply rate results from the increased change in resistance, an effect already accounted for. The effect on the dissipation rate concerns changes in total emissive power, an effect also already accounted for. The advantage of a tungsten filament over a Gem filament in the heat-

${ }^{1}$ Temperatures in the thermodynamic centigrade scale are commonly measured in degrees $\mathrm{K}$. (Kelvin), the zero of which scale is the absolute zero of temperature. ${ }^{\circ} \mathrm{K} .={ }^{\circ} \mathrm{C} .+273^{\circ}$. 
ing portion of a flash, resulting from the higher operating temperature of the former, is thus about 1.6.

Factor (5), relating to the luminous efficiency of radiation, is the most important factor in the contrast of speeds. It concerns the supply rate and the amount of heat that is stored up. In the preceding paragraphs, equality of voltage and of wattage has been the basis on which lamps have been rated as equivalent. A more just basis, since the eye is the instrument by which flashing signals are tested, is one of equality of voltage and of luminous output. It is in this transition that luminous efficiency considerations enter. Contrasting an efficiency of 4. I lumens per watt for the Gem lamp with 9.2 lumens per watt for the tungsten lamp at $2400^{\circ} \mathrm{K}$, shows that for equivalent lamps from the visual standpoint, the wattage of the tungsten lamp should be only about 45 per cent. of the wattage of the Gem lamp. Considering now two lamps of the same filament material, differing in wattage in this same ratio, it follows that the smaller filament is only 77 per cent. as long, 59 per cent. as great in diameter and 27 per cent. as great in mass as the larger filament. The combined effect of the decreased filament mass and decreased supply rate leads to a flashing speed in favor of the smaller filament equal to about 1.7. Evidently this reasoning may be applied to the case where filament materials are contrasted. The advantage of a tungsten filament over a Gem filament in the heating portion of a flash resulting from differences in the luminous efficiencies of their radiations is thus of the order of $\mathbf{I} .7$.

Combining the several advantages possessed by tungsten, one would expect that a tungsten lamp flashed in a constant voltage circuit to its normal operating temperature, would reach 90 per cent. of its maximum brightness in somewhat more than one-sixth of the time required by an equivalent Gem lamp flashed to its normal operating temperature. At the time this comparison was conceived the apparatus described later had been dismantled, so that no direct experimental verification of the preceding considerations is offered. However, computations according to the method indicated later point to the real contrast in speeds of the two lamps as being about $1: 6.5$. This is a very satisfactory agreement indicating the correctness of the analysis.

The cooling portion of a flash might be analyzed similarly. However, such a comparison is relatively of much less importance 
in contrasting filaments for flashing speeds, because the time required for a filament to cool to a negligible fraction, say 5 per cent., of its maximum brightness, is always small in comparison with the time required to heat to 95 per cent. of the maximum brightness. Briefly stated, such an analysis summarized shows that a tungsten lamp during the cooling portion of a flash will respond about 2.5 times as rapidly as the equivalent Gem lamp. The stperiority of a tungsten over a Gem filament in incandescent signal lamps is decisive.

In this work, started in response to a request for the development of a unit for use in daylight signalling, emphasis is laid upon variations in tungsten-filament lamps, since simple considerations like those stated above showed them to be much more desirable than any known lamps containing filaments of different material.

\section{EXPERIMENTAL METHOD.}

The experimental study of flashing speeds was based upon a method used previously. ${ }^{2}$ It consisted in making instantaneous candlepower measurements of a flashing lamp at various instants following the beginning or ending of a current flash.

The arrangement of apparatus used is diagrammed in Fig. I. $L_{1}$ represents the lamp being flashed, $L_{2}$ a comparison lamp operated under steady current conditions, $P$ an ordinary photometer head for instantaneous candlepower comparisons of $L_{1}$ with $L_{2}$. The flashing of $L_{1}$ was brought about by the periodic making and breaking of the current through it by means of the electromagnetically operated switch $S$. Regularity of action and the precise value of the period depended upon the synchronous motor which operated two sliding contacts $C_{1}$ and $C_{2}$ in the same circuit with the electromagnet of the switch. Positiveness in the action of the switch was secured by means of a spring as shown, which tended to keep it open. Ordinarily the adjustments were such that the circuit containing $L_{1}$ was closed only during a quarter turn of the drum $D_{1}$. Drum $D_{2}$ mounted on the same shaft as $D_{1}$ carried an adjustable point contact $C_{4}$, which closed once each rotation of the drum, the circuit containing the relay $R$ for a very brief interval only. The operation of $R$ in turn jerked aside momentarily a small opaque screen at the opening of the photometer eyepiece $O$. For any particular setting of the point

"Lighting Journal, Nov. I915; Phys. Rez', I2 p. I99, Igr8. 
contact on $D_{2}$, there was a definite phase relation between the exposure of the opening at $O$ and the flash of the lamp $L_{1}$. This condition permitted the observer, in arriving at candlepower com-

FIG. I.
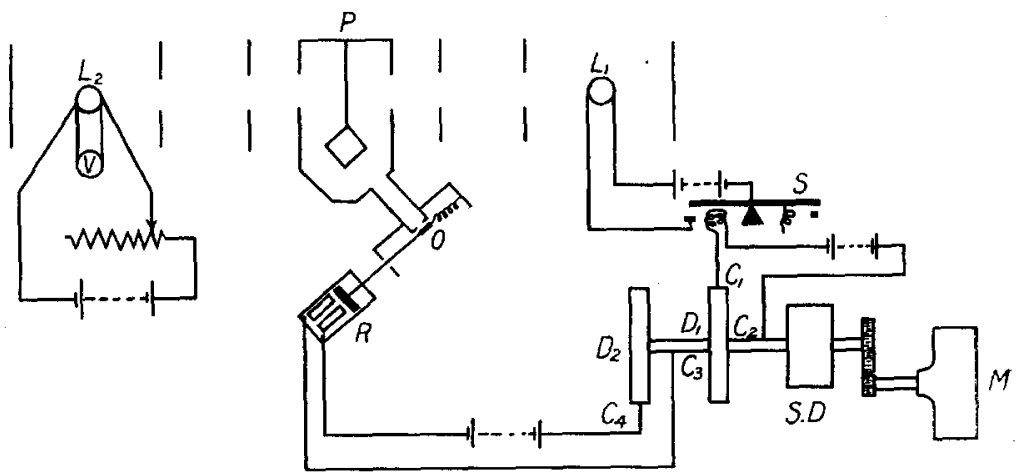

Apparatus for testing speed of signal lamps.

parisons between $L_{1}$ and $L_{2}$, to use any desired number of successive glimpses of the photometric field.

The method of procedure consisted in judging for some definite setting of the contact $C_{4}$, the momentary deviations from equality in the photometric match, adjusting the current through

FIG. 2.

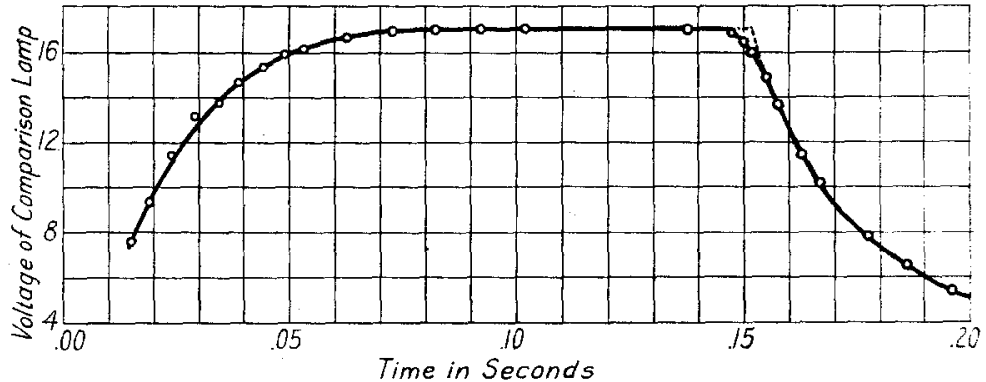

The voltage of a comparison lamp required to match in candlepower a 6-volt, 2-ampere, argonfilled, ribbon-filament signal lamp on flashing, as a function of time.

lamp $L_{2}$ for equality, and noting the voltage of lamp $L_{2}$. Then the operator adjusted the contact $C_{4}$ to a new position and proceeded as before. From a number of such readings, a curve may be platted, showing the voltage of the comparison lamp $L_{2}$ as a function of the time elapsing since the beginning of the flash in the 
lamp $L_{1}$. Such data for a special argon-filled, ribbon-filament lamp" are platted in Fig. 2. "The consistency of the observations is well shown. Given further the relation between voltage and candlepower for lamp $L_{2}$ there follows at once, as shown in Fig. 3. the candlepower variations of the special lamp during a flash. In this case the lamp practically reached its maximum steady condlepower in somewhat less than a tenth of a second. On cooling off the luminous output fell to a few per cent. of its maximum value in considerably less than a twentieth of a second. The consistency obtainable in measurements of this character is shown in Table I, in which certain speed characteristics are given for various lamps proposed for signal purposes.

FIG. 3.

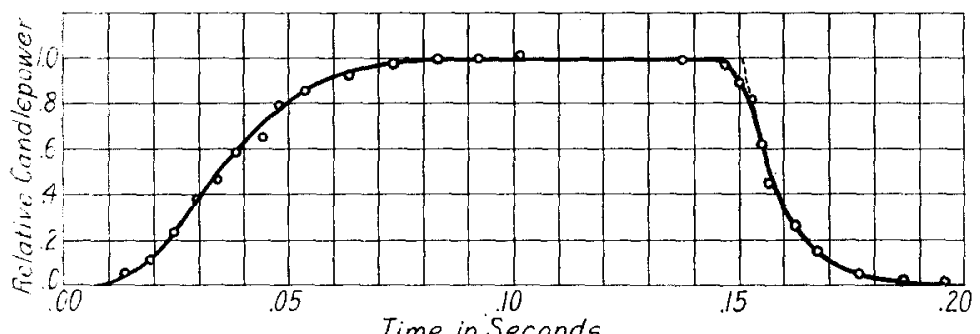

The cardiepower as a function of time for a 6-volt, 2-ampere, argon-filled, ribbon-filament signal lamp, on flashing.

It is evident that the observed curves, in case strictly instantaneous glimpses could have been obtained, would have followed much the paths indicated by the dotted lines in Figs. 2 and 3 ; but, due to the aperture at $O$ being open for an appreciable interval, the cooling effect became manifest previous to the coincidence in time of the interruption of the flashing current and the centre of the time interval during which the opening at $O$ was uncovered. This is quite analogous to the effects due to finite slit-widths in spectrophotometry. The difference in time given by the intercepts of the full and dotted curves on the steady maximum candlefower line represents one-half of the interval of exposure of the photometric field. The total exposure in this instance, as well as

: This lamp was a preliminary lamp of the type recommended by the Nela Research Laboratory for use in a 6-volt, 2-amp. signalling unit for the U. S. signal Corps. The possibility of manufacturing ribbon filament lamps has depended upon the production of satisfactory ribbon filaments, an accomplishment brought about by Dr. C. F. Lorenz, formerly of this laboratory. 
TABLE I.

Data on Ribbon and Wire Filament Signal Lamps Showing Consistency in Speed Measurements.

\begin{tabular}{|c|c|c|c|c|c|c|c|c|}
\hline \multirow{2}{*}{ Lamp } & \multirow{2}{*}{ Description } & \multirow{2}{*}{$\begin{array}{c}V \\
\text { in } \\
\text { Volts }\end{array}$} & \multirow{2}{*}{$\begin{array}{c}I \text { in } \\
\text { Amperes }\end{array}$} & \multirow{2}{*}{$r / R_{m} \mid$} & \multirow{2}{*}{$T$} & \multicolumn{2}{|c|}{ Heating* } & \multirow{2}{*}{$\begin{array}{l}\text { Cooling } \\
t .2-t . z\end{array}$} \\
\hline & & & & & & $t_{.2}-t_{0}$ & $t .7-t .2$ & \\
\hline $26 \mathrm{~L}$ & $\begin{array}{l}\text { Very open double spiral } \\
\text { o.025 mm. ribbon fila- } \\
\text { ment in argon at } 600 \\
\text { mm. pressure }\end{array}$ & 7.05 & 2.15 & 0.12 & $3020^{\circ} \mathrm{K}$ & & \begin{tabular}{|l}
0.019 sec. \\
.020 \\
.025 \\
.015 \\
.019 \\
.019 \\
.017 \\
.020
\end{tabular} & $\begin{array}{l}0.016 \mathrm{sec} . \\
.013 \\
.0 \mathrm{rg}\end{array}$ \\
\hline $80 \mathrm{~S}$ & $\begin{array}{l}\text { Very open double spiral } \\
\text { o.o83 mm. wire fila- } \\
\text { ment in nitrogen at } \\
600 \mathrm{~mm} \text {. pressure }\end{array}$ & 5.80 & I.9r & .04 & 2980 & $\begin{array}{l}0.036 \mathrm{sec} . \\
.037 \\
.036 \\
.039\end{array}$ & $\begin{array}{l}.030 \\
.028 \\
.026 \\
.027 \\
.031 \\
.031\end{array}$ & $\begin{array}{l}.014 \\
.015\end{array}$ \\
\hline $\mathrm{S}-133-\mathrm{Ar}$ & $\begin{array}{l}\text { Moderately open single } \\
\text { spiral } 0.027 \mathrm{~mm} \text {. rib- } \\
\text { bon filament in argon } \\
\text { at } 600 \mathrm{~mm} \text {. pressure }\end{array}$ & 6.60 & I. 84 & .16 & 3020 & $\ldots \ldots$ & $\begin{array}{l}.031 \\
.029 \\
.026 \\
.030 \\
.028 \\
.030\end{array}$ & .017 \\
\hline
\end{tabular}

* $t_{0}, t_{.2}$, and $t_{.7}$ respectively refer to the time at which the flash began, the time at which the filament possessed 0.2 of its maximum brightness, and the time at which it possessed 0.7 of its maximum brightness.

for a large part of the work reported here, was approximately o.oio second. It is possible to correct these curves and to obtain others showing the results of truly instantaneous glimpses, but generally the accuracy of the observations does not justify this, and such corrections have therefore not been made.

\section{EXPECTATIONS BASED ON STEADY CURRENT MEASUREMENTS.}

Before discussing the experimental data, let us consider the flashing speeds which steady current measurements lead us to expect. We shall assume that there is no lag or lead of radiation with respect to resistance ${ }^{4}$ during the rapid changes of temperature incident to the flashing of a filament. For a circuit containing no resistance external to the flashing lamp, equation ( $\mathrm{I}$ ) reduces to

$$
\frac{V^{2}}{R}=W+c m \frac{d T}{d t},
$$

in which $V$ represents the steady voltage of the battery; $R$ the resistance of the lamp; $W$ the steady wattage corresponding to $R$; and the other symbols the quantities as already mentioned. Solving for $\frac{d t}{d T}$, we have

$$
\frac{d t}{d T}=\frac{c m}{\frac{V^{2}}{R}-W} .
$$

${ }^{4}$ Worthing, Phys, Rev., 12, p. I99, 1918: Gæhr. Phys. Rev., 12, p. 396, 1918. 
This equation, together with data showing the relation between resistance, wattage and temperature for a succession of steady states, serve for the computing of the time $d t$ required, for any small change in temperature, $d T$. The summation of such small intervals of time over any arbitrarily chosen temperature range gives directly the time required to heat the filament through that temperature range. Similar summations for a number of arbitrarily chosen temperature ranges serve for the platting of a curve

FIC. 4 .

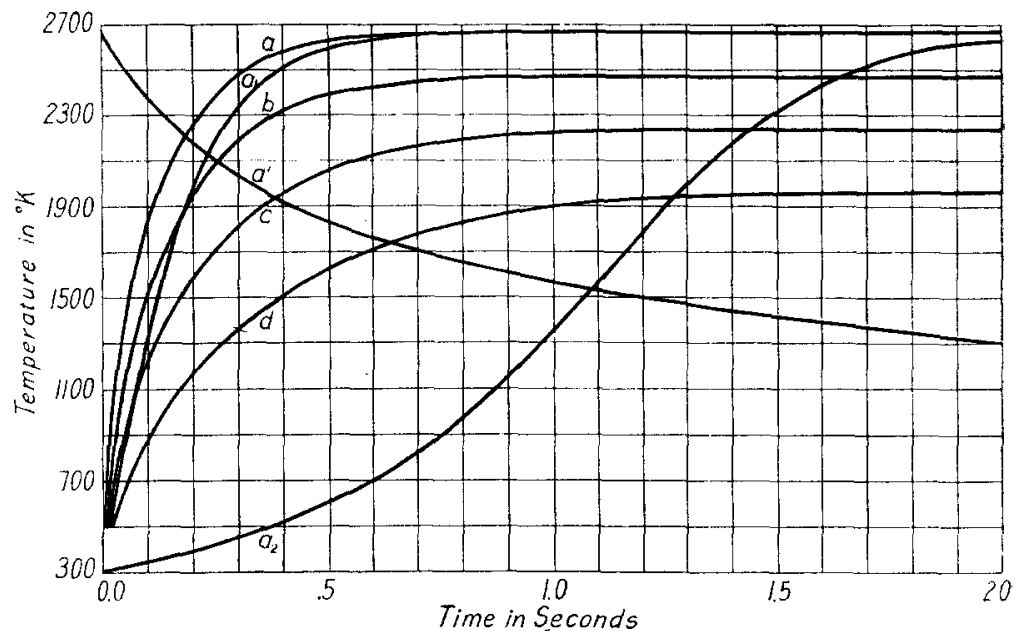

Heating and cooling curves for a $0.258 \mathrm{~mm}$. tungsten filament in vacuo-lamp A-33.

$\begin{array}{cccc}\text { Curve } & \text { Condition } & r / R_{m} & T \\ a & \text { Heating } & 0 & 2667^{\circ} \mathrm{K} . \\ b & \text { Heating } & 0 & 2478^{\circ} \mathrm{K} \\ c & \text { Heating } & 0 & 2232^{\circ} \mathrm{K} . \\ d & \text { Heating } & 0 & 1973^{\circ} \mathrm{K} . \\ \boldsymbol{a}_{1} & \text { Heating } & . \mathrm{I} 7 & 2667^{\circ} \mathrm{K} . \\ \boldsymbol{a}_{t} & \text { Heating } & \infty & 2667^{\circ} \mathrm{K} \\ a^{\prime} & \text { Cooling } & - & 2667^{\circ} \mathrm{K} .\end{array}$

showing the temperature of a flashing filament as a function of time.

Making use of the relations between $R, W, T$, and $c$, found for a certain tungsten vacuum lamp, ${ }^{\bar{\nu}} A-33$, flashing curves were computed for various conditions of operation. Fig. 4, curves $a, b, c$, and $d$, represent four such curves computed for this lamp in constant voltage circuits containing no resistance other than that of the lamp filament. The curves show that the 
flashing speed for a given filament diameter increases rapidly with increase in the maximum temperature.

The term $\frac{V^{2}}{R}$ of equation (2) is ordinarily zero during the cooling process, and the changes which take place depend only on the state of the filament itself. It follows that whatever the maximum temperature of the flash, the cooling curves for a given filament through a specified temperature range are identical. For example, a filament heated to $2500^{\circ} \mathrm{K}$, after cooling to $2000^{\circ} \mathrm{K}$, will thereafter cool exactly as though heated initially only to $2000^{\circ} \mathrm{K}$.

FIG. 5 .

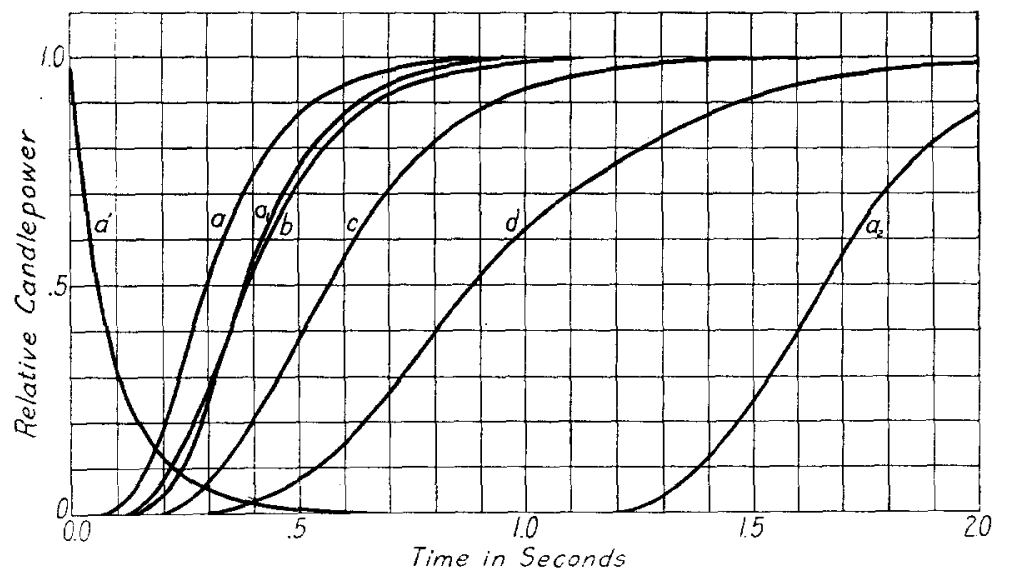

Candlepower time curves corresponding to the temperature time curves of Fig. 4 .

When the circuit contains resistance external to the flashing lamp equation (3) reduces to:

$$
\left(\frac{V}{R+r}\right)^{2} R=W+c m \frac{d T}{d i}
$$

where $r$ represents the external resistance. A contrast of curves $a$ and $a_{1}$, Fig. 4, shows the effect of the introduction of a moderate resistance; a contrast of curves $a$ and $a_{2}$ the effect of an extremely large resistance. In this instance, the ordinarily favorable effect of the positive-temperature coefficient of the tungsten filament has become an equally great detriment to rapid flashing.

Fig. 5 shows the brightness curves corresponding to the temperature curves given in Fig. 4. The desirability of a high operating temperature and a circuit free from external resistance 
for rapidity of flashing are perfectly evident. The most evident effect of an external resistance, as has been stated already, is a delay in the appearance of incandescence. It is also to be noted that the time required in cooling down from the maximum brightness to say 5 per cent. of that value is considerably less than that required to heat from room temperature to within the same per cent. of the maximum value, that is to 95 per cent. of the maximum value. This agrees with what has been said already regarding the predominating importance of the heating portion of a flash in determining flashing speeds. This conclusion may seem at variance with common observations on effects noticeable on switching on and off ordinary lamps. The apparent discrepancy is to be ascribed largely to the inertia of the pupillary aperture of the eye and to changes in the retina sensitiveness to light stimuli. On the flashing up of a lamp both factors operate to give the impression of a maximum brightness, or of an overshooting in brightness while the filament is still relatively far from the actual maximum brightness.

Corresponding curves for filaments of the same material, but of different radii, may be obtained from the curves of Fig. 4 and Fig. 5. It may be readily shown, referring to equation (3), that $\frac{V^{2}}{R}$ and $W$ for a given length of wire both vary as the radius of the filament, while the mass varies as the square of this dimension. This results in corresponding values for $\frac{d t}{d T}$ varying directly as the radii. Therefore, for a filament whose diameter is $0.0258 \mathrm{~mm}$., one-tenth that of the filament considered in Figs. 4 and 5, corresponding curves may be obtained at once from the curves of those figures by dividing the time intervals by ten.

Curves $a$ and $b$, Fig. 6, show the computed results for a vacutum lamp having a filament whose diameter is $0.0134 \mathrm{~mm}$. for the condition of no resistance external to the lamp and for a condition of a resistance equal to about one-sixth that of the filament when at $2667^{\circ} \mathrm{K}$, the approximate conditions occurring in experimental work with this same size of filament.

The flashing speed for a filament immersed in a gas may be computed on the supposition that the lamp filament on heating up passes through a succession of steady states; that is, on assuming that a filament on passing through $\mathrm{I} 5 \mathrm{OO}^{\circ} \mathrm{K}$ on its way to a 
maximum temperature of $2500^{\circ} \mathrm{K}$ is radiating and losing energy by gaseous conduction and convection at the same rate as it radiates and loses energy in consequence of the gas when operated at a steady temperature of $\mathrm{I}_{500}^{\circ} \mathrm{K}$. Equations (3) and (4)

FIG. 6.

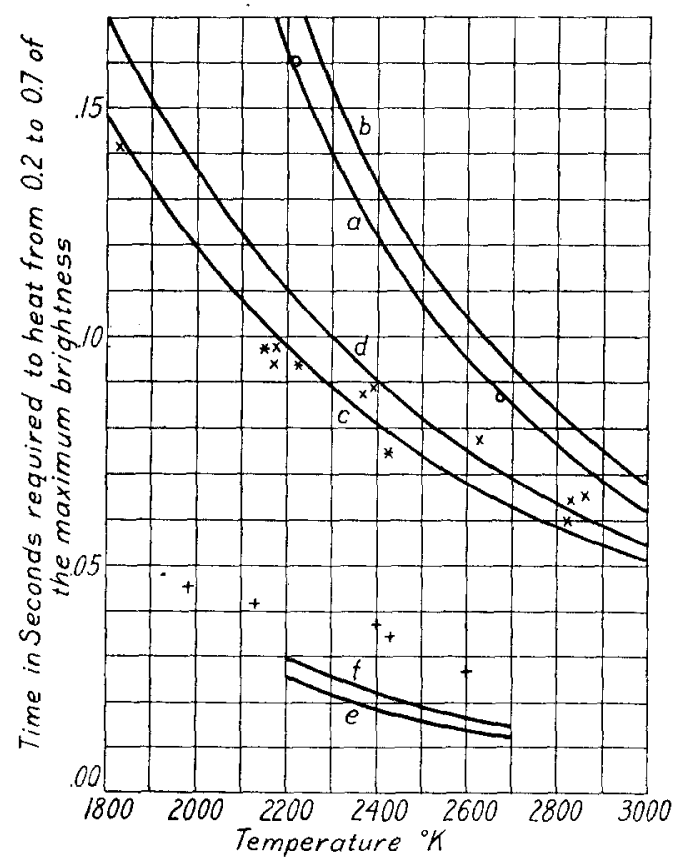

Times required for lamps with $0.134 \mathrm{~mm}$. tungsten wire filaments to heat from 0.2 to 0.7 of their maximum brightnesses under various conditions, usually corresponding roughly to computed curves $b, d$ and $f$.

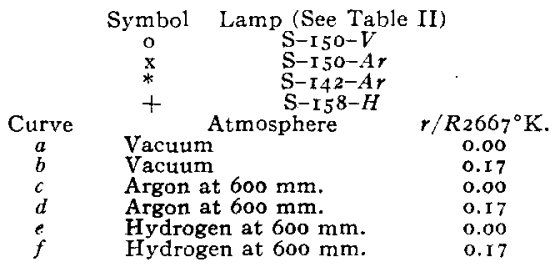

then become applicable to gas-filled lamps as well as to vacuum lamps. It should be noted here that the quantity $W$ includes the gas loss. Following this plan, curves $c$ and $d$ of Fig. 6 have been computed for a o.or $34-\mathrm{mm}$. tungsten filament in argon, and curves $e$ and $f$ for the same lamp when hydrogen filled. Due to 
changes in the relative importance of gas conduction with change in filament size, one cannot compute the speeds for one size of filament in terms of those for another size by the simple method shown for vacuum lamps.

EXPERIMENTAL RESULTS.

For comparisons of signalling speeds it is necessary to aclopt some criterion of flashing speed. Since all candlepowertime curves seem to have the same shape and to differ mainly in their relative slopes, a measure of their relative slopes would seem a fair criterion. This criterion is not all that could be wished since it does not take account of the time interval required for the filament to reach incandescence. As a measure of this slope and criterion, we have arbitrarily adopted the time required for a filament in heating from two-tenths to seven-tenths of its maximum brightness. This represents referring to Fig. 3, the time of passage through what is sensibly the straight portion of the heating curve. Thereby, also, the errors due to the finite lengths of the glimpses of the photometric field in the experimental work were largely eliminated.

Observed values for such speed criterions are contrasted in Table II and Fig. 6 with the computed values for various lamps. While the agreements are not all that could be desired, they are not bad considering experimental difficulties.

Certain causes for these outstanding differences may be briefly stated. (I) Due to the finite length of glimpses in the photometric measurements, observed values for $t_{T}-t_{2}$ may be expected to be too great, the more so the smaller the value of $t_{7}-t_{2}$. Consideration of apparent lengths of glimpses indicates negligible effects for $S-142-A r, S-150-A r$ and $S-150-V$; but in the case of $S-140-A r$ and $S-$ I $58-H$ these effects may amount to Io per cent. or more. (2) The end coolings of the filaments in $S-150-A r, S-150-V$ and $S-158-H$ were different from those in the lamps used in computation. Their influence becomes more and more prominent with decreasing temperature of flash. Just how this would affect the results is difficult to say. (3) Hydrogen molecules, as shown by Langmuir," dissociate at high temperatures. Above $2000^{\circ} \mathrm{K}$ or $2100^{\circ} \mathrm{K}$, the fractional part

'Trans. Am. Electrochem. Soc., 20, p. 225. I9I ; Phys. Rev., 34. p. 401, 1912; Jour. Am. Chem. Soc., 34, p. 860, 1912. 
of the molecules in a given mass that are thus split becomes quite appreciable. Flashing lamps containing hydrogen, therefore, possess an added method of disposing of energy supplied, which does not occur appreciably in other lamps. A hydrogen lamp as its filament heats up is required to establish and maintain a more and more completely ionized atmosphere. There is in effect

TABLE II.

Observed and Computed Values of the Rates of Heating and Cooling of Various Tungsten Filaments.

\begin{tabular}{|c|c|c|c|c|c|c|c|c|c|}
\hline \multirow{3}{*}{ Lamp } & \multirow{3}{*}{ Description } & \multirow{3}{*}{$R \frac{r}{m}$} & \multirow{3}{*}{$\begin{array}{c}\text { Maxi- } \\
\text { mum } \\
\text { tempera- } \\
\text { ture of } \\
\text { flash }\end{array}$} & \multicolumn{4}{|c|}{ Heating * } & \multirow{2}{*}{\multicolumn{2}{|c|}{$\frac{\text { Cooling * }}{t .2-t .7}$}} \\
\hline & & & & \multicolumn{2}{|c|}{$t .2-t_{0}$} & \multicolumn{2}{|c|}{$t . \pi-t .2$} & & \\
\hline & & & & $\begin{array}{l}\text { Obs. } \\
\text { Sec. }\end{array}$ & $\begin{array}{l}\text { Comp. } \\
\text { Sec. }\end{array}$ & $\begin{array}{l}\text { Obs. } \\
\text { Sec. }\end{array}$ & $\begin{array}{c}\text { Comp. } \\
\text { Sec. }\end{array}$ & $\begin{array}{l}\text { Obs. } \\
\text { Sec. }\end{array}$ & $\begin{array}{l}\text { Comp. } \\
\text { Sec. }\end{array}$ \\
\hline \multirow[t]{2}{*}{$S-I 4 O-A T$} & $\begin{array}{l}\text { Straight } 0.039 \mathrm{~mm} \text {. } \\
\text { filament in argon } \\
\text { at } 600 \mathrm{~mm} \text {. }\end{array}$ & $\begin{array}{r}0.010 \\
.011 \\
.013\end{array}$ & $\begin{array}{l}2780^{\circ} \mathrm{K} \\
2490 \\
2220\end{array}$ & $\begin{array}{l}0.021 \\
.026 \\
.028\end{array}$ & $\begin{array}{l}0.014 \\
.018 \\
.022\end{array}$ & $\begin{array}{l}0.022 \\
.022 \\
.024\end{array}$ & $\begin{array}{l}0.013 \\
.016 \\
.019\end{array}$ & $\begin{array}{r}0.009 \\
.007 \\
.010\end{array}$ & $\begin{array}{r}0.0056 \\
.0058 \\
.0058\end{array}$ \\
\hline & Strajght $0 \mathrm{ram}$ & .009 & 2720 & .024 & .015 & .023 & .014 & 027 & \\
\hline \multirow{4}{*}{$S-I 42-A T$} & filament in argon & $\begin{array}{l}.00 \\
.12 \\
.8\end{array}$ & 2220 & $\begin{array}{l}.072 \\
.130\end{array}$ & .000 & .000 & $\begin{array}{l}.002 \\
.102\end{array}$ & $\begin{array}{l}.027 \\
.039\end{array}$ & $\begin{array}{l}.030 \\
.036\end{array}$ \\
\hline & at $600 \mathrm{~mm}$. & 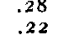 & $\begin{array}{l}1855 \\
2420\end{array}$ & $\begin{array}{l}.216 \\
.104\end{array}$ & $\because 33$ & $\begin{array}{l}.103(?) \\
.075\end{array}$ & $\begin{array}{l}.162 \\
.090\end{array}$ & $\begin{array}{l}.036 \\
.028\end{array}$ & $\begin{array}{l}.039 \\
.034\end{array}$ \\
\hline & & .15 & 2165 & .153 & .166 & .098 & . IIO & .043 & .037 \\
\hline & & .16 & 1980 & .183 & .193 &. $\mathrm{I}$ IO(?) & .134 & .035 & .038 \\
\hline \multirow[t]{7}{*}{$S-I 50-A r$} & $\begin{array}{c}\text { Openly coiled o. } 134 \\
\mathrm{~mm} \text {. filament in }\end{array}$ &. $\mathrm{I}_{4}$ & 2845 & $.09 \mathrm{I}$ & .077 & .066 & .062 & & \\
\hline & $\begin{array}{l}\mathrm{mm} \text {. flament in } \\
\text { argon at } 600 \mathrm{~mm} \text {. }\end{array}$ & $\begin{array}{l}-18 \\
.19\end{array}$ & $\begin{array}{l}2015 \\
2380\end{array}$ & $\begin{array}{l}.10 \mathrm{I} \\
. \mathrm{I} 33\end{array}$ & $\begin{array}{l}.106 \\
.137\end{array}$ & .077 & .075 & & \\
\hline & & .17 & 2 I 90 & .158 & .163 & .094 & .109 & & \\
\hline & & $.2 \mathrm{I}$ & 2395 & .127 & .140 & .085 & $.09 \mathrm{I}$ & & \\
\hline & & .24 & I860 & .234 & .247 & .141 & .150 & & \\
\hline & & .14 & 2825 & .087 & .080 & .065 & .063 & & \\
\hline & & (?) & 2 rgo & .150 & (?) & .098 & .109 & & \\
\hline \multirow[t]{2}{*}{$S-I 50-V$} & Openly colled o.134 & .14 & 2680 & .097 & $.09 \mathrm{r} t$ & .086 & .095 & & \\
\hline & $\begin{array}{l}\text { mm. filament in } \\
\text { vacuo. }\end{array}$ & .17 & 2220 &. $\mathrm{I} 4 \mathrm{I}$ & $.154 t$ & .160 & .174 & .053 & .060 \\
\hline \multirow[t]{5}{*}{$\mathrm{S}-\mathrm{I} 58-\mathrm{H}$} & Openly coiled 0.134 & .18 & 2125 & .068 & $.04 \mathrm{I}$ & $.04 \mathrm{I}$ & $\ldots \ldots$ & .013 & .008 \\
\hline & $\mathrm{mm}$. filament in & .57 & 2420 & .050 & .034 & $.02 \mathrm{I}$ & $\ldots$ & .013 & .008 \\
\hline & hydrogen at & .14 & 2600 & .035 & .028 & .017 & $\cdots$ & .012 & .007 \\
\hline & & .10 & $\begin{array}{l}2405 \\
1975\end{array}$ & $\begin{array}{l}.047 \\
.050\end{array}$ & .039 & .022 & & & \\
\hline & & & & & & & & & \\
\hline
\end{tabular}

* $t_{0}, t_{.2}$ and $t_{.7}$ respectively refer to the time at which the flash began, the time at which the filament possessed 0.2 of its maximum brightness, and the time at which it possessed 0.7 of its maximum brightness.

$t$ Account has been taken here of the fact that in the vacuum lamp the filament did not cool to sensibly room temperature between flashes.

an added appreciable method of storage of energy for the filament not considered in equations (2) and (3). This factor is extremely difficult to allow for, but, when taken into consideration, must lead to greater computed values for $t_{7}-t_{2}$, thus lessening the outstanding difference between the observed and the computed values. A contrast of results on $S$-I I $40-A r$ and $S-$ I58-H lends credence to this view. (4) The supposition that filaments in gas-filled lamps pass through a succession of steady states is not completely fulfilled. This unquestionably accounted for several 
cases of burn-outs on first flash in some low-roltage signal lamps which were operated at exceptionally high temperatures, though the same lamps had previously withstood for some time the same high temperatures when brought to them gradually.

Summarizing the tests on the flashing speeds, it appears that computed values for the times required to reach two-tenths of the maximum brightness $\left(t_{2}-t_{0}\right)$ and to go from this condition to seven-tenths of the maximum brightness $\left(t_{.7}-t_{.2}\right)$ on heating, and then to cool through this same range $\left(t_{.2}-t_{.7}\right)$ agree well with the observed values in the vacuum and argon-filled lamps containing o. I34-mm. filaments. Considering sources of error, the differences in $S-140-A r$ and $S-I_{5} 8-H$ nay well be accounted for. If we except hydrogen-filled lamps in which ionization occurs, we probably are not far wrong in assuming that the true values of the speed criterions may be obtained by computation, using the method outlined above. In general we may say in comparing various types of tungsten filament lamps, that the time required for a filament to heat to approximately maximum brightness exceeds greatly the time required in cooling to approximately ztro brightness; that the higher the maximum temperature of a flash the greater the flashing speed; that the smaller the filament the greater the flashing speed; that a given filament in hydrogen flashes more rapidly than in argon, and more rapidly in argon than in vacuo.

\section{SPEED FUNCTION FOR RATING LAMPS.}

It has already been noted in connection with Fig. 5, that the general form of the candlepower-time curve for a tungsten filament in vacuo, in a constant voltage circuit is not much changed by changing the maximum temperature of the flash or by introducing a small external resistance in the circuit. It might be added that changes in filament size and immersion in gas are likewise of little effect in changing the general aspects. This leads one to suspect that some function might be found which would represent the facts well enough to be taken as a cue to the speed of the lamp. With this in mind consider the rate of change of brightness of a filament with time at or near the maximum temperature during the heating portion of a flash. Equation (4) on rearranging gives

$$
\frac{d T}{d t}=\frac{W_{m}}{c m}\left[\frac{R / R_{m}}{\left(\frac{R+r}{R_{m}+r}\right)^{2}}-\frac{W}{W_{m}}\right]
$$



in which $\theta$ may be considered constant for values of $T / T_{m}$ nearly equal to unity. There follows

(It) $\quad \frac{I}{B} \frac{d B}{d t}=\theta \frac{I}{T} \frac{d T}{d t}$

Substitution of $\frac{d T}{d t}$ from ( I I) in (I4) and the elimination of $T_{\text {: }} T_{m}$ by means of an expansion of ( 3 ) give

$$
\frac{I}{B} \frac{d B}{d t}=Q \frac{B_{m}-B}{B_{m}}
$$

Thus it appears expressing brightness in terms of the maximum, that the rate of increase in brightness in the neighborhood of that maximum is also proportional to $Q$. Similarity of heating curves suggests, in comparing the speeds of various lamps over any fixed relative brightness range, that while ( 15 ) would not hold, the deviations for the different lamps would be found approximately the same, and that the function $Q$ would still serve for comparison purposes; for instance, that

(16) $Q\left(t_{.7}-t_{.2}\right)=$ constant (approx.)

That the function $Q$, one involving only steady current measurements of wattage, resistance and temperature, in the neighborhood of the maximum temperature of a flash, together with the thermal capacity of the filament, thus involving no candlepower considerations directly, should give the cue to the flashing speed from the light standpoint is on first thought somewhat surprising.

To what extent (16) may be used in representing the results computed on a rigid basis may be seen by referring to Table III. Inspection of the table shows approximate constancy in the product $Q\left(t_{.7}-t_{.2}\right)$ first with change in the maximum temperature of the flash and second with change in resistance external to the flashing lamp, and third with change in the atmosphere surrounding the filament. Insofar as there is agreemerit, or lack of agreement, between the experimental and the computed speeds shown in Table II and Fig. 6, there is also agreement or failure on the part of equation ( I6) in representing actual speed data. Evidently, in a very real sense, the function $Q$ gives the cue to the flashing speed of the lamp and may well be considered the speed function. Different lamps may reasonably be rated as to their flashing speeds through their corresponding $Q^{\prime} s$.

Vol. ToI, No. II42-Is 


\section{COMPARISON OF VARIOUS SIGNAL LAMPS FROM DIFFERENT VIEWPOINTS.}

The question of flashing speed in considering lamps for signalling purposes is not all important. Usually one is concerned with lamps of a specified voltage, a specified average life-say twenty-five hours-and a specified luminous output.

TABLE III.

Data Showing with What Approximation Equation (I6) Represents Computed Speeds for Various Tungsten Filament Lamps Under Different Condiions of Operations.

\begin{tabular}{|c|c|c|c|c|c|c|c|c|c|c|}
\hline Lamp $\ddagger$ & $T$ & $\begin{array}{c}W \\
\text { watts }\end{array}$ & $\underset{\text { ohms }}{R}$ & $\begin{array}{c}(C M) \\
\text { joules } / \\
\text { degree }\end{array}$ & $\boldsymbol{\beta}$ & $\alpha$ & $\frac{R-r}{R+r}$ & $\frac{Q}{1 / \sec .}$ & $\begin{array}{c}\left(t .7-t_{.2}\right) \\
\text { com- } \\
\text { puted }\end{array}$ & $Q\left(t .7-t_{.2}\right)$ \\
\hline \multirow[t]{6}{*}{$A-33 \ldots$} & $3000^{\circ} \mathrm{K}$. & 136.5 & 2.016 & 0.0216 & $4 \cdot 40$ & 1.20 & 1.00 & $\mathrm{I} \mathrm{I} .80$ & $0.120 \mathrm{sec}$. & 1.42 \\
\hline & 2667 & $8 I . I$ & I. 753 & .0205 & 4.52 & I. 20 & I.00 & 8.49 & .167 & 1.42 \\
\hline & 2667 & $8 \mathrm{I} . \mathrm{I}$ & 1.753 & .0205 & 4.52 & I. 20 & $.7 \mathrm{I}$ & 7.95 & .184 & I. 44 \\
\hline & 2667 & $8 \mathrm{I} . \mathrm{I}$ & 1.753 & .0205 & 4.52 & I. 20 & .00 & 4.92 & .327 & I. $6 \mathrm{I}$ \\
\hline & 2232 & 35.30 & I. 412 & .6190 & 4.73 & I. 20 & $\mathrm{x} .00$ & 4.9 .3 & .295 & I. 45 \\
\hline & I 800 & I 2.37 & I.095 & .0175 & 4.99 & I. 20 & 1.00 & 2.43 & .619 & 1.50 \\
\hline \multirow[t]{4}{*}{$\mathrm{S}-\mathrm{I} 42-\mathrm{Ar}$} & 3000 & 80.7 & 5.78 & .00452 & 3.443 & I. 225 & .74 & 35.9 & .0547 & I. 42 \\
\hline & 2667 & 54.3 & 5.01 & .00429 & 3.3 I 5 & 1.225 & .70 & I 9.8 & .0712 & I. 4 I \\
\hline & 2232 & 30.5 & 4.03 & .00397 & 3.122 & I. 225 & .65 & I 3.4 & .1063 & 1.43 \\
\hline & I 800 & I6.0 & 3.09 & .00365 & 2.888 & I. 225 & .56 & 8.85 & I 70 & 1.50 \\
\hline$S-I 42-N$ & 3000 & 90.3 & 5.78 & .00452 & 3.28 & J.213 & .74 & 27.9 & .0504 & 1.41 \\
\hline \multirow{3}{*}{$\mathrm{S}-\mathrm{I} 53-\mathrm{H}$} & 2667 & 243.8 & $5.0 \mathrm{I}$ & .00429 & 4.33 & I. 225 & .72 & I I I & .0157 & 1.72 \\
\hline & 2478 & 184.1 & 4.58 & .00416 & 3.65 & I. 225 & .68 & 80 & .0173 & 1.58 \\
\hline & 2232 & 133.3 & 4.03 & .00397 & 2.65 & 1.225 & .64 & 51.6 & .028 & 1.45 \\
\hline \multirow[t]{3}{*}{$\mathrm{S}-\mathrm{I} 40-\mathrm{Ar}$} & 3000 & 3.3 .5 & 70.4 & .000393 & 2.98 & I. 20 & I.00 & I I.9 & .0114 & I. 36 \\
\hline & 2232 & I 5.0 & 49.4 & $.00034^{6}$ & 2.37 & I. 20 & 1.00 & 69.4 & .0192 & I. .33 \\
\hline & 1973 & I I. 23 & 42.6 & .000329 & 2.22 & I. 20 & 1.00 & 59.3 & $.023 \mathrm{I}$ & I. 36 \\
\hline $59 \mathrm{~L}$. & 3000 & 13.15 & 3.31 & .000247 & $4.0 \mathrm{I}$ & 1.3 .5 & .79 & 90 & .01657 & I. 48 \\
\hline $80 \mathrm{~S}$. & 2980 & I 1.07 & 3.04 & .000331 & 3.42 & 1.33 & .92 & 52 & $.0290 \dagger$ & 1.51 \\
\hline
\end{tabular}

$\ddagger$ Descriptions of these lamps follow:

\begin{tabular}{|c|c|c|c|c|c|}
\hline Lamp & Filament shape & $\begin{array}{l}\text { Filament } \\
\text { diameter }\end{array}$ & $\begin{array}{l}\text { Dimensions } \\
\text { length }\end{array}$ & Atmosphere & $\begin{array}{l}\text { Cooling due } \\
\text { to supports }\end{array}$ \\
\hline $\begin{array}{l}\mathrm{A}-33 \ldots \ldots \\
\mathrm{S}-\mathrm{I} 42-\mathrm{Ar} \ldots \\
\mathrm{S}-\mathrm{I} 42-\mathrm{N} \\
\mathrm{S}-\mathrm{I} 53-\mathrm{H} \ldots \\
\mathrm{S}-\mathrm{I} 40-\mathrm{Ar} \ldots \\
59 \mathrm{~L} \ldots \ldots \\
80 \mathrm{~S} \ldots \ldots\end{array}$ & $\begin{array}{l}\text { Straight wire } \\
\text { Straight wire } \\
\text { Straight wire } \\
\text { Very open } 1 \text { y } \\
\text { coiled wire... } \\
\text { Straight wire } \\
\text { Very open ly } \\
\text { coiled ribbon.. } \\
\text { Very openly } \\
\text { coiled wire... }\end{array}$ & $\begin{array}{l}0.258 \mathrm{~mm} . \\
0.134 \\
0.134 \\
0.134 \\
0.039 \\
0.021 \\
0.19 \\
0.083\end{array}$ & $\begin{array}{l}10.85 \mathrm{~cm} . \\
8.5 \\
8.5 \\
8.5 \\
8.2 \\
1.65 \\
1.65\end{array}$ & $\begin{array}{l}\text { Vacuo } \\
\mathrm{A} \text { at } 600 \mathrm{~mm} \text {. } \\
\mathrm{N} \text { at } 600 \mathrm{~mm} \text {. } \\
\mathrm{H} \text { at } 600 \mathrm{~mm} \text {. } \\
\mathrm{A} \text { at } 600 \mathrm{~mm} \text {. } \\
\mathrm{A} \text { at } 600 \mathrm{~mm} \text {. } \\
\mathrm{N} \text { at } 600 \mathrm{~mm} \text {. }\end{array}$ & $\begin{array}{l}\text { None. } \\
\text { Present. } \\
\text { Present. } \\
\text { Present. } \\
\text { Present. } \\
\text { Present. } \\
\text { Present. }\end{array}$ \\
\hline
\end{tabular}

Average of two observations.

$\dagger$ Average of six observations.

Most of the data and discussions herein have referred to filaments of a definite size. But now, with a knowledge of the approximate constancy expressed in equation ( I6), of the life of a filament as a function of its temperature and of its surrounding atmosphere, and of the gas losses in different gases as a function of the filament dimensions, it is possible to determine the flashing speeds of any sized filament for probable conditions of operation. Thus Table IV gives first the characteristics of a single filament 
of tungsten operated in various atmospheres at a fixed temperature, and, second, the characteristics of varying sized filaments in the same atmospheres operated under conditions to produce the same luminous flux, the same average life and the same specified voltage. The computations involved while simple in theory are quite tedious. Of course the exactness of the values recorded depends upon the correctness with which the relations used repre-

TABle IV.

Characteristics of Lamps Containing Tungsten Filaments in Various Atmospheres Computed for Conditions - $(A)$ filament dimensions and maximum temperature constant; (B) lamp voltage, luminous flux and life conslant.

\begin{tabular}{|c|c|c|c|c|c|c|c|c|}
\hline \multirow{2}{*}{$\frac{\text { Condition }}{\text { Atmesphere }}$} & \multicolumn{4}{|c|}{$A$} & \multicolumn{4}{|c|}{$B$} \\
\hline & Vacuum & $\begin{array}{c}A \mathrm{at} \\
600 \mathrm{~mm}\end{array}$ & $\begin{array}{c}N \text { at } \\
600 \mathrm{~mm}\end{array}$ & $\left|\begin{array}{c}H \text { at } \\
600 \mathrm{~mm} .\end{array}\right|$ & Vacuum & $\begin{array}{c}A \text { at } \\
600 \mathrm{~mm} .\end{array}$ & $\mid \begin{array}{c}N \text { at } \\
600 \mathrm{mn} .\end{array}$ & $\begin{array}{c}H \text { at } \\
600 \mathrm{~mm} .\end{array}$ \\
\hline $\begin{array}{l}\text { Temperature in } \\
\text { degrees } \mathrm{K} . \\
\text { Filament }\end{array}$ & 2800 & 2800 & 2800 & 2800 & 2725 & 3070 & 3050 & 2990 \\
\hline $\begin{array}{l}\text { Filament length } \\
\text { in centimeters } \\
\text { Filament diam- }\end{array}$ & 8.24 & 8.24 & 8.24 & 8.24 & $6.2 \mathrm{I}$ & 2.96 & 2.90 & 2.16 \\
\hline $\begin{array}{r}\text { eter in } \mathrm{mm} . \\
\text { Voltage........ }\end{array}$ & $\begin{array}{c}0.134 \\
14.65\end{array}$ & $\begin{array}{l}0.134 \\
18.45\end{array}$ & $\begin{array}{l}0.134 \\
19.7\end{array}$ & $\begin{array}{l}0.134 \\
39.55\end{array}$ & $\begin{array}{c}0.098 \\
\mathbf{I} 2\end{array}$ & $\begin{array}{c}0.073 \\
\mathrm{I} 2\end{array}$ & $\begin{array}{c}0.079 \\
12\end{array}$ & $\begin{array}{l}0.134 \\
12\end{array}$ \\
\hline $\begin{array}{l}\text { Wattage .... } \\
\text { Current in am- }\end{array}$ & 40.4 & 64.0 & 73.0 & 294 & 10.7 & 19.8 & 23.8 & 100 \\
\hline & 2.755 & 3.47 & 3.70 & $7 \cdot 4.4$ & I. 64 & 1.65 & $x .08$ & 8.3 \\
\hline $\begin{array}{l}\text { in lumens } \\
\text { Efficiency }\end{array}$ & 747 & 747 & 747 & 747 & 322 & 322 & 322 & 322 \\
\hline$\frac{\text { lumens }}{\text { watt }} \ldots$ & I 8.5 & II. 7 & 10.4 & 2.54 & $16.35^{\circ}$ & 16.3 & 13.5 & 3.22 \\
\hline$\frac{\mathrm{E}_{c r}}{\mathrm{E}_{\imath}} \ldots \ldots \ldots$ & 1.00 & 1.58 & I. $8 \mathrm{I}$ & 7.3 & 1.00 & I.66 & 1.95 & 7.67 \\
\hline Life in hours.. & 12.7 & I I I IO & 890 & 254 & 25 & 25 & 25 & 25 \\
\hline${ }^{a} \ldots \ldots \ldots$ & $\begin{array}{l}1.22 \\
4.48\end{array}$ & $\begin{array}{l}\mathrm{I} .22 \\
3.37\end{array}$ & $\begin{array}{l}1.22 \\
3.4^{2}\end{array}$ & $\begin{array}{l}1.22 \\
4.79\end{array}$ & $\begin{array}{l}1.22 \\
4.51\end{array}$ & $\begin{array}{l}1.22 \\
3.21\end{array}$ & $\begin{array}{l}1.22 \\
3.42\end{array}$ & $\begin{array}{l}I .22 \\
5.40\end{array}$ \\
\hline C in $\frac{\text { degrees }}{\text { joules }} \ldots$ & .00439 & .00439 & .00439 & .00439 & .00173 & .00485 & .00557 & .00109 \\
\hline$Q$ in $\frac{\mathrm{I}}{\sec } \ldots \ldots$ & 18.7 & 2.39 & 27.6 & 144 & 23.9 & 59.8 & 65.0 & 203 \\
\hline $\begin{array}{l}O(t .7-t .2) \\
(t .7-t .2) \text { in sec. }\end{array}$ & $\begin{array}{l}\mathrm{I} .42 \\
.076\end{array}$ & $\begin{array}{l}\mathrm{I} .42 \\
.059\end{array}$ & $\begin{array}{l}1.42 \\
.052\end{array}$ & $\begin{array}{l}\mathrm{I} .42 \\
.0 \mathrm{IO}\end{array}$ & $\begin{array}{l}\mathrm{I} .4^{2} \\
.059\end{array}$ & $\begin{array}{l}1.42 \\
.024\end{array}$ & $\begin{array}{l}\mathrm{I} .42 \\
.022\end{array}$ & $\begin{array}{l}\text { I. } 42 \\
.0070\end{array}$ \\
\hline
\end{tabular}

sent facts. Inasmuch as the signalling type of incandescent lamp differs greatly in fundamental principles of construction from ordinary commercial lamps, it naturally follows that much of the data upon which Table IV is based has not been subjected to repeated thorough tests. To illustrate, considerations of speed and of covering a desired field when used with a mirror for directing the flux into a beam, may require very open coils of the filament in the signal lamp in contrast with the tightly closed coils of ordinary lamps. The effect of this on gas-loss data is evident : 
the effect on life considerations, while not so evident, is possibly just as real.

The writer has assumed in computing results given in Table IV that the life of very open coiled or straight filament lamps to depend solely on the rate of vaporization, as is the case for commercial, straight-filament, vacuum lamps. A meagre reference by Mackay ${ }^{\top}$ on the relative decrease in the vaporization of tungsten in a nitrogen atmosphere, some data obtained in the Research Laboratory at Schenectady on a comparison between argon-filled and nitrogen-filled lamps, and some simple life tests conducted by the writer's colleague, Dr. C. F. Lorenz, have led the writer to conclude that atmospheres of nitrogen and of commercial argon at $600 \mathrm{~mm}$. pressure reduce the rates of vaporization of tungsten filaments immersed in them to respectively about one-seventieth and one-ninetieth of the rate in vacuo. Or what is the same, the lives of lamps with filaments immersed in these atmospheres will be about 70 and 90 times as long as the lives of lamps with filaments in vacuo. As to the life of a tungsten filament in a hydrogen atmosphere, there is much greater uncertainty. Little is known beyond the fact that it is much less than that for the same filament at the same temperature in argon or nitrogen. Assuming the rate of vaporization to depend on the diffusion of the tungsten vapor away from the filament, the application of the diffusion theory due to Stefan and Winkelmann, ${ }^{8}$ leads to a life in hydrogen equal to about two-ninths of that in argon. We shall probably not be far from the truth by assuming, as we have here, the life of a given filament at a given temperature in vacuo, in argon, in nitrogen, and in hydrogen to vary as $1: 90: 70: 20$. For the variation in the rate of vaporization of tungsten in vacuo with temperature, the results of the classic investigation of Langmuir's ${ }^{9}$ corrected to the scale of temperature ${ }^{10}$ now generally accepted have been used. His results thus corrected are given fairly closely by the equation

$$
\log m=21.56-\frac{47570}{T}-3.30 \log T
$$

where $m$ represents the rate of vaporization in grams per $\mathrm{cm} .^{2}$ per

\footnotetext{
${ }^{7}$ Trans. I. E. S., Sept., 1914, p. 745.

${ }^{8}$ Winkelmann, "Handbuck der Physik," I, p. 1429.

"Phys. Rev., 2, p. 329, I9I3; Phys. Rev., 10, p. 377, 1917.

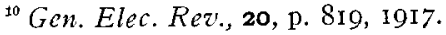


second. This is connected with actual life data through the commercial experience that the 6o-watt, I Io-volt, vacuum lamp--diameter of $0.050 \mathrm{~mm}$.- -at $2440^{\circ} \mathrm{K}$ has a life of I000 hours. ${ }^{11}$

For the gas losses from small filaments for use in compiling Table IV, the writer has taken his own data. Defining $E$ as the rate of dissipation of energy per unit of surface area and thus including gas losses together with radiation, it has been found that the results obtained may be expressed with considerable exactness over the temperature range $1800^{\circ} \mathrm{K}$ to $3000^{\circ} \mathrm{K}$ by empirical formulæ of the type.

$$
E=A+B(\log T-3 \cdot 3)+C(\log T-3 \cdot 3)^{2}
$$

The constants $A, B$ and $C$ for a given atmosphere depend on the diameter of the filament. Values for a filament diameter of o. I34 mm. are given in Table $\mathrm{V}$ for various atmospheres. Given

TABLE V.

Values of the Constants $A, B$ and $C$ of Equation ( $I 8$ ) Consistent with Expressing $E$ in Watts per Square Centimetre for a $0.134 \mathrm{~mm}$. Cylindrical Tungsten Wire in Various Atmospheres. Due to Disregarding the Thermal Expansion of the Filament, E is Really Expressed in Watts per Square Centimetre of Filament Surface as Measured at Room Temperature.

\begin{tabular}{|c|c|c|c|}
\hline Atmosphere & A & $B$ & C \\
\hline Vacuum $\ldots \ldots \ldots \ldots$ & 1.379 & 4.87 & I.40 \\
\hline Argon (commercial) at $600 \mathrm{~mm}$. pressure. & 1.792 & 3.00 & 1.25 \\
\hline Nitrogen at $600 \mathrm{~mm}$. pressure . . . . . . . & I.859 & 2.83 & 2.00 \\
\hline Hydrogen at $600 \mathrm{~mm}$. pressure ..... & $2.45^{8}$ & $\mathrm{I} .6 \mathrm{I}$ & 10.8 \\
\hline
\end{tabular}

$E$ as a function of $T$ for one filament diameter for a given atmosphere, a corresponding value for a filament with another diameter in the same atmosphere may be readily obtained by the following empirical relation which holds fairly well for filaments varying in diameter from $0.03 \mathrm{~mm}$. to $0.3 \mathrm{~mm}$.

(19)

$$
\frac{\left[\frac{E_{a}}{E_{v}}-I\right]_{1}}{\left[\frac{E_{a}}{E_{v}}-I\right]}=\left[\frac{d_{u}}{d_{1}}\right]^{x}
$$

where $E_{a}$ and $E_{r}$ correspond respectively to a filament in a gaseous atmosphere and in a vacuum and $d$ the filament diameter. For

${ }^{11}$ This in reality represents a rated life which is noticeably less than the experienced life. No material error in argument is introduced by this assumption of equality. 
argon and nitrogen $x^{*}$ approxinuates 0.70 for hydrogen 0.75 . Equation ( 19) states in general terms that the gas losses vary inversely as the 0.7 or 0.75 power of the filament diameters.

Other necessary data ${ }^{12}$ used in compiling Table IV are well known, or are such as may be obtained from a consideration of what has been given already. The cooling effects of filament supports, which may be considerable in very low-voltage lamps, have been ignored here. It is probable that the values of $\left(t_{.7}-t_{.2}\right)$ computed for the hydrogen lamps are too small because of ionization effects.

A study of Table IV suggests certain general laws applicable to flashing signal lamps which, while not proven, may be shown to be true.

(I) For a given filament operated in various gases, including in vacuo at a fixed maximum temperature, the flashing speed is greatest in that lamp for which the gas loss is greatest.

(2) For cylindrical filament lamps of the same open construction possessing the same luminous flux and life on a specified voltage, the flashing speed is the greatest in that lamp for which the gas loss is greatest.

(3) For cylindrical filament lamps of the same open construction possessing the same luminous flux and same life when operated at some fixed voltage, the efficiency of the vacuum lamp is less than that of the gas-filled lamp for large sized filaments. The reverse is true for small-sized filaments. In condition $B$, Table IV, the efficiency of the vacuum lamp is greater than that of the nitrogen or the hydrogen lamps, and very nearly the same as that of the argon lamp. For a slightly larger filament the reverse would be true for the argon lamp.

(4) For cylindrical filament lamps of the same open construction possessing the same luminous flux and the same life on a specified voltage, the filament is shortest in the lamp possessing the greatest gas loss. This consideration is of importance in lamps which are used with mirrors or lenses to give intensified beams, in that the longer the filament the more effectively may one cover a certain field or area containing the observer to whom signals are sent.

${ }^{12}$ Worthing: Phys. Rev', 10, p. 377, 1917; 12, p. 199, 1918; Bul. A. I. M. and M. E., Sept., I919; Hyde, G., E. Rev., 2o, p. 819, 1917; Hyde, Cady and Forsythe, Phys. Rea'., ro, p. 8ig, igiz. 
(5) For cylindrical filament lamps of the same open construction possessing the same luminous flux and the same life on a specified voltage, the temperature is lowest in the vacuum lamp and highest in that gas-filled lamp which has the least gas loss. This may be of importance where the color of the light is a factor.

RIBBON FILAMENTS VS. WIRE FILAMENTS.

For equal radiating surfaces a ribbon filament possesses a much less mass of material to be heated than does an equivalent wire filament and therefore will inherently respond the more rapidly on flashing. The flashing speed of a given ribbon filament in vacuo is quite closely equal to that of a wire filament whose diameter is twice the thickness of the ribbon, as follows directly from considering the ratios of the surfaces of the filaments to their masses. Lack of actual equality in gas-filled lamps is due to a difference in gas loss. The great desirability of a ribbon filament in signal lamp construction depends on the fact that through thinness any desired flashing speed is obtainable and that through variations in width any desired current-carrying capacity. A ribbon filament combines the current-carrying capacity of a large wire filament with the high speed of a small wire filament. Contrasting wire and ribbon filaments of the same current-carrying capacity operated at the same temperature. We find that considerations of life are unfarorable to the ribbon filament. Vaporization of the filament material at a given rate in a given length of time produces a greater relative change in the mass of the ribbon filament than in that of the equivalent wire filament. We therefore expect to operate the ribbon filament at a reduced temperature. However, as an offset to this, the ribbon form may possibly be favored somewhat in the vaporization rate and in the gas loss due to the lines of flow of vapor and of heat being on the whole parallel near the ribbon filament in contrast to the spreading lines of flow about the wire filament. A few careful measurements which have been made indicate an appreciable factor in favor of the ribbon form in cutting down gas losses. However, the great advantage of a ribbon form, considering everything, is the possibility offered by the ribbon filament in increased efficiency without loss of speed by changing from a gas with a great gas loss to one with a small gas loss. Thus it was felt, in planning to meet the demands for a 6-rolt, 2-ampere lamp for warfare, that a 
proposed lamp containing a wire filament should be filled with nitrogen, while the ribbon filament lamp might be filled with argon. Flashing speeds for preliminary lamps of these two types from which the final selection was made, No. 26L, No. 59L, and No. 80 S, which illustrate these deductions have already been referred to in Tables I and III.

No speed tests were carried out with 6-volt, 2-ampere signal lamps with ribbon and wire filaments operating at temperatures such as to yield a 25 -hour life. However, starting with the curve of Fig. 3 and the speed data of $59 \mathrm{~L}$ and $80 \mathrm{~S}$, given in Table III, it is not difficult to tell what such curves will be like. Fig. 7 shows what is to be expected for the two types as well as for a ribbon

Fig. 7,

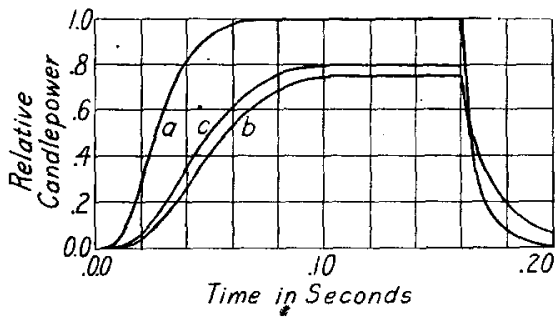

Expected speed of performance for three 6-volt, 2-ampere tungsten-filament signal lamps operated at temperatures corresponding to about 25 hours of life. $a$. $0.021 \mathrm{~mm}$. ribbon filament in an argon atmosphere. $b$. Ribbon flament of the same thickness in vacuo, $c .0 .084 \mathrm{~mm}$. wire filament in a nitrogen atmosphere. The cooling curve for the wire-filament lamp (not shown) lies generally near the cooling curve of $(a)$. The corresponding maximum temperatures are approximately $3020^{\circ} \mathrm{K}, 2660^{\circ} \mathrm{K}$. and $3050^{\circ} \mathrm{K}$.

in vacuo. (Due to neglecting end-coolings in Tables IV, some discrepancies will be found between the data there given and that represented in this figure.) The advantage of the ribbon filament in argon over the wire filament in nitrogen in flashing speed is seen to be approximately 1.6 , in luminous efficiency 1.25 . The reason for the actual selection of lamps with ribbon filaments in argon for warfare signalling is apparent.

It is interesting to note certain tests conducted by the writer's colleague, W. E. Forsythe. ${ }^{1: 3} \quad$ Using sometimes a special sectored disk, so cut as to give at will various combinations of dot-and-dash signals when rotated before a steady light source, and at other times a special commutator for producing at will any one of the same combinations of dots and dashes by flashing a signal lamp, he found, using 6-volt, 2 -ampere lamps, ( I ) that the maxi-

${ }^{13}$ Phys. Rev., 16, p. 62, 1920. 
mum speed of reception of signals using signal lamps with ribbon filaments in argon did not differ noticeably from that using the rotating sector and a steady source, which presumably offers the maximum possible speed; (2) that the speeds of reception of signals were noticeably greater when using lamps with ribbon filaments in argon than when using lamps with the same filaments in racuo; and (3) that the speeds of reception of signals were noticeably greater-roughly of the order that might be expected irom Fig. 7-when using lamps with ribbon filaments in argon than when using lamps with wire filaments in nitrogen.

\section{CONCLUSION.}

The selection of a lamp for signalling purposes which shall have a given life and luminous flux at a specified voltage naturally depends on various factors such as the rapidity of the flash, the size and the intensity of the beam from the unit of which the lamp is a part, the luminous efficiency of the lamp either for all visible wave-lengths or for some limited region of the spectrum, and the ruggedness of structure. Certain factors will naturally be of greater importance than others and may be decisive in making a selection. So far as speed and efficiency are concerned, what has been said indicates clearly that a lamp containing a ribbon filament in argon represents the preferred type of construction for use in a 6-volt, 2-ampere signalling unit. In a future paper entitled "The Theory of Signalling Units Employing Incandescent Lamp Sources." the author intends to discuss the characteristics of the beam from a signalling unit.

The writer is greatly indebted to Mr. Kenneth Moorhead who has assisted throughout the investigations, particularly in the making of the speed measurements.

Cleveland, Ohio,

November, I920.

American Beet Sugar. (Sugar, December, 1920, p. 690.)American beet sugar is expected to harvest a larger California crop this year, according to present indications. Its coast campaign has just been completed with satisfactory results and about 20 per cent. of its full outturn produced in the Rocky Mountain States, yielding 100,000 bags more than in 1919-1920. Indications are that its total output this year will be between $1,400,000$ and $1,500,000$ bags, against I, 077,000 for the previous campaign. 